\title{
A Fast and Accurate Method for Power System Voltage Sag Detection
}

\author{
Adnan Romi Diwan*1, Khalid M. Abdulhassan ${ }^{2}$, Falih M. Alnahwi ${ }^{3}$ \\ ${ }^{1}$ Electrical Engineering Department, University of Basrah, Basrah, Iraq \\ ${ }^{2}$ Electrical Engineering Department, University of Basrah, Basrah, Iraq \\ ${ }^{3}$ Electrical Engineering Department, University of Basrah, Basrah, Iraq
}

\begin{abstract}
Correspondence
*Adnan Romi Diwan

Electrical Engineering Department

University of Basrah, Basrah, Iraq.

Email: adnanalromi57@gmail.com
\end{abstract}

\begin{abstract}
In order to mitigate the effect of voltage sag on sensitive loads, a dynamic voltage restorer (DVR) should be used for this purpose. The DVR should be accompanied with a fast and accurate sag detection circuit or algorithm to determine the sag information as quickly as possible with an acceptable precision. This paper presents the numerical matrix method as a distinctive candidate for voltage sag detection. The design steps of this method are demonstrated in detail in this work. The simulation results exhibit the superiority of this technique over the other detection techniques in term of the speed and accuracy of detection, simplicity in implementation, and the memory size. The results also accentuate the recognition capability of the proposed method in distinguishing different types of voltage sag by testing three different voltage sag scenarios.
\end{abstract}

KEYWORDS: Voltage sag, Sag detection, Numerical matrix detection, and Sag compensation.

\section{INTRODUCTION}

In modern days, the voltage sag is considered as one of the prominent problems in the power systems because of its direct effect on the sensitive loads [1]. The voltage sag can be defined according to IEEE Std. 1159-1995 as, "A decrease to between 0.1 and $0.9 \mathrm{pu}$ in rms voltage or current at the power frequency for durations of 0.5 cycles to 1 minute."[2]. The compensation of the drop caused by the voltage sag should be provided due to the expansion in using some industrial loads that are sensitive to any variation in the voltage level such as computers, process controllers, PLC, and robotics. Many methods are used to mitigate the voltage sag effect and compensate the missing voltage due to the sag. Dynamic Voltage Restorer (DVR) device is the most commonly used device to compensate the voltage sag issues [3-7]. In order to compensate the voltage sag effectively, a fast sag detection method should be adopted. Therefore, the detection method should have a prompt response in detecting the starting and ending instants of the sag as well as the sag depth.

There are many different techniques that are used to detect the voltage sag occurrence such as Fourier Transform method, Phase Locked Loop (PLL)method, Vector Control technique, Peak value supply method, and Wavelet Transform technique [8],[9]. The evaluation of each method is based on the speed of sag detection and the accuracy in determining the sag depth. The implementation costs and complexity of each method should be taken into account in addition to the sag detection accuracy.

In this paper, the Numerical Matrix Detection Method is adopted as a fast, accurate, and simple voltage sag detection technique. The algorithm of this method is attached to a voltage sag compensation circuit to highlight the importance to the accurate detection. The method is explained and implemented using MATLAB simulation environment. The simulation results reveal the high speed and the accuracy of numerical matrix detection method.

In addition, the results show the capability of this method in recognizing the voltage sag shape by considering three different scenarios for the voltage sag.

\section{Some Voltage SAg Detection Methods}

The following sub-sections demonstrate some prominent methods for voltage sag detection. In addition, this section also presents the methodology of voltage sag detection that is followed by each detection technique as well as their advantages and drawbacks.

\section{a) Fourier Transform Method}

This method can be applied to each phase of the supply voltage. The main advantage of this technique is that it can handle both of the magnitude and phase shift of every frequency component of the supply voltage. In addition, it is very effective in the presence of the higher order harmonics [9]. 
In practice, Windowed Fast Fourier Transform (WFFT) is used since it has the same characteristics of Fourier Transform. In addition, it is very easy to be implemented in real time systems [9]. However, in order to accurately recover the magnitude and phase shift of the supply voltage, WFFT requires a delay in the sag detection process approaching to one cycle after the starting instant of the sag. Therefore, it is considered to be a slow detection method [10],[11].

\section{b) Phase Locked Loop (PLL) Technique}

The Phase Locked Loop (PLL) is used to track the frequency and the phase angle of the supply voltage. Any deviation from the normal operation conditions can easily be detected in this method [9], [12].

This method is used for phase angle detection only and cannot recover the information of the sag depth, and it is not easy to be implemented in real time [9]. Besides, it is not an accurate detection method and not suitable for fast detection conditions [13],[14].

c) Vector Control/Software Phase Locked Loop (SPLL)

Actually, it is an improvement of PLL in term of the speed of detection and the implementation facilities. SPLL can easily be implemented in real time by using digital signal processing (DSP).

The advantage of this method is that it can introduce fast detection process [9], [13], [15].

\section{d) Peak Value of the Supply Waveform Detection Technique}

A simple principle adopted in this technique that is based on the peak value of the voltage waveform [12]. This peak value voltage is compared with a desired reference voltage. If the difference between the two values exceeded the limit values, then the compensation circuit will operate to inject the missing voltage [11].

The drawbacks of this technique are:

1) The delay in detection time may be reach up to $0.5 \mathrm{sec}$.

2) The presence of noise significantly affects the measurement process.

3) The reference voltage should be generated separately in order to obtain information about the phase shift.

\section{e) Wavelet Transform Technique (WT)}

The signal in this method can be represented in both time and frequency domains. The benefit of this technique is the rapid detection of the disturbances, but the drawbacks of this method are:

1) Difficulty in interpreting the results directly.

2) Not easy to implement in real time.

3) It requires a large memory size.

4) It has a delay associated with mother wavelet [16].

\section{NuMERICAL MATRIX METHOD}

Numerical matrix method has several advantages over the aforementioned methods. It has a very small response time when implementing and recovering the system abnormalities. Furthermore, it is very compatible with the real time implementation and requires a very small memory size. This method can be applied on each phase separately. Moreover, it can detect the starting and the end instants of the sag, the depth of the sag, and the phase shift. The basic operation principle of this technique is based on sampling the supply voltage and store the data information in matrix form as shown in Fig.(1).

\section{a) Single Harmonic Numerical Matrix}

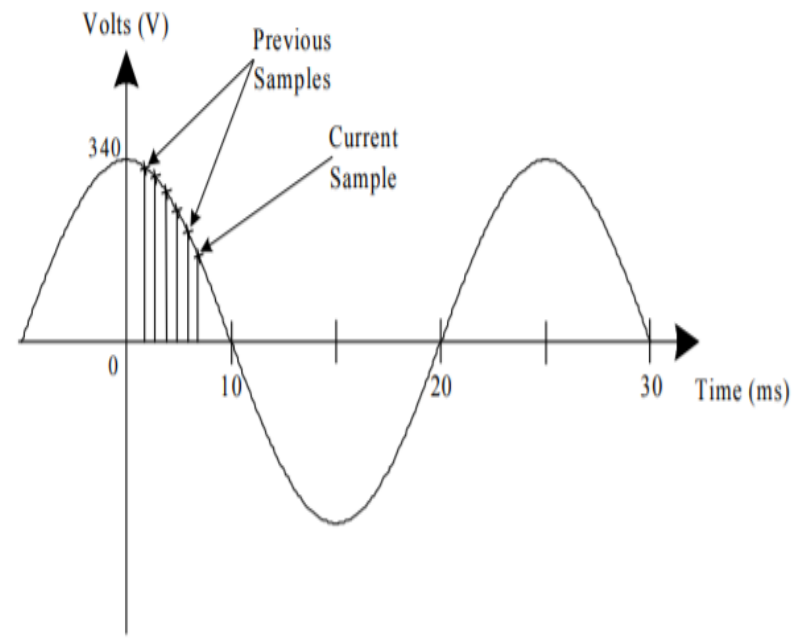

Fig. 1: Supply voltage sampled at regular intervals [9].

This matrix implementation requires just two samples of the supply voltage signal ( $V_{\text {supplypresent and }}$ $\left.V_{\text {supply past } 1}\right)$ to construct $2 \times 2$ detection matrix. The samples of the supply voltages can be expressed as follows:

$$
\begin{gathered}
V_{\text {supply present }}=|V| \cos (\omega t+\phi) \\
V_{\text {supply past } 1}=|V| \cos (\omega t-\omega T+\phi)
\end{gathered}
$$

where $|V|$ represents the magnitude of the supplied voltage, $\omega$ represents angular frequency, $\phi$ denotes the phase of the supplied voltage, and $T$ is the sampling period. By disregarding the time variation part $(\omega t)$, the above equations can be re-written as:

$$
\begin{gathered}
V_{\text {supply present }}=|V| \cos (\phi) \\
V_{\text {supply past } 1}=|V| \cos (\phi-\omega T)= \\
|V| \cos (\omega T) \cos (\phi)+|V| \sin (\omega T) \sin (\phi)
\end{gathered}
$$

These equations can be represented in matrix form as follows:

$$
\left[\begin{array}{c}
V_{\text {supply present }} \\
V_{\text {supply past } 1}
\end{array}\right]=\left[\begin{array}{cc}
1 & 0 \\
\cos (\omega T) & \sin (\omega T)
\end{array}\right]\left[\begin{array}{l}
|V| \cos (\phi) \\
|V| \sin (\phi)
\end{array}\right](5)
$$

Assuming that $\left(A=\left[\begin{array}{cc}1 & 0 \\ \cos (\omega T) & \sin (\omega T)\end{array}\right]\right),(|V| \cos (\phi)=$ $u)$ and $(|V| \sin (\phi)=v)$ which represents the in-phase and the quadrature phase components. These components can be evaluated by rearranging Equation (5) as follows:

$$
\left[\begin{array}{l}
u \\
v
\end{array}\right]=A^{-1}\left[\begin{array}{c}
V_{\text {supply present }} \\
V_{\text {supply past } 1}
\end{array}\right]
$$

The magnitude and the phase of the supply voltage can be calculated as:

$$
\begin{gathered}
|V|=\sqrt{u^{2}+v^{2}} \\
\phi=\tan ^{-1} \frac{v}{u}
\end{gathered}
$$

Although the single harmonic matrix representation is very simple and requires only two samples to predict the 
voltage signal magnitude, it may results in a singular matrix due to the small value of the sampling time $(\mathrm{T})$. In other words, the value of $\mathrm{T}$ should be as small as possible to provide accurate calculations and fast processing, so the determinant of matrix $A$ will be very small. As a result, the elements of the inverse of the matrix $A$ would be so huge. Therefore, the matrix calculations will consider the presence of an additional harmonic (say the fifth harmonic) to avoid the singularity of matrix $A$.

\section{b) Numerical Matrix with Two Harmonics}

As mentioned in the previous sub-section, the fifth harmonic is considered to be presented to avoid the singularity of matrix $A$. Consequently, four samples are needed to predict the magnitude and the phase of each harmonic. The equations of each sampled value of the supply voltage are given by:

$$
\begin{aligned}
& V_{\text {supply present }}=\left|V_{1}\right| \cos \left(\omega_{1} t+\phi_{1}\right)+ \\
& \left|V_{5}\right| \cos \left(\omega_{5} t+\phi_{5}\right) \\
& V_{\text {supply past } 1}=\left|V_{1}\right| \cos \left(\omega_{1} t-\omega_{1} T+\phi_{1}\right)+ \\
& \left|V_{5}\right| \cos \left(\omega_{5} t-\omega_{5} T+\phi_{5}\right) \\
& V_{\text {supply past } 2}=\left|V_{1}\right| \cos \left(\omega_{1} t-2 \omega_{1} T+\phi_{1}\right)+ \\
& \left|V_{5}\right| \cos \left(\omega_{5} t-2 \omega_{5} T+\phi_{5}\right) \\
& V_{\text {supply past } 3}=\left|V_{1}\right| \cos \left(\omega_{1} t-3 \omega_{1} T+\phi_{1}\right)+ \\
& \left|V_{5}\right| \cos \left(\omega_{5} t-3 \omega_{5} T+\phi_{5}\right)
\end{aligned}
$$

where:

$\left|V_{1}\right|$ : Magnitude of the fundamental component $(50 \mathrm{~Hz})$.

$\left|V_{5}\right|$ : Magnitude of the 5 th harmonic $(250 \mathrm{~Hz})$.

$\phi_{1}$ : Phase of the fundamental component with respect to a cosine wave.

$\phi_{5}$ : Phase of the fifth harmonic with respect to a cosine wave.

$\omega_{1}$ : Angular frequency of the fundamental component.

$\omega_{5}$ : Angular frequency of the fifth harmonic.

$\mathrm{T}$ : Sampling period.

$V_{\text {supply present }}$ : Present sample of the supply voltage.

$V_{\text {supply past(1-3) }}$ : Previous samples of the supply voltage.

By doing the same mathematical manipulations followed in the single harmonic calculations, the matrix $\mathrm{A}$ is extended to the following form:

$$
\begin{aligned}
& A= \\
& {\left[\begin{array}{cccc}
1 & 0 & 1 & 0 \\
\cos \left(\omega_{1} T\right) & \sin \left(\omega_{1} T\right) & \cos \left(\omega_{5} T\right) & \sin \left(\omega_{5} T\right) \\
\cos \left(2 \omega_{1} T\right) & \sin \left(2 \omega_{1} T\right) & \cos \left(2 \omega_{5} T\right) & \sin \left(2 \omega_{5} T\right) \\
\cos \left(3 \omega_{1} T\right) & \sin \left(3 \omega_{1} T\right) & \cos \left(3 \omega_{5} T\right) & \sin \left(3 \omega_{5} T\right)
\end{array}\right]}
\end{aligned}
$$

Consider $u_{1}$ and $u_{5}$ to be the in-phase components of the first and fifth harmonics, respectively. Similarly, assume $v_{1}$ and $v_{5}$ to be the quadrature phase components of the first and fifth harmonics, respectively. The values of each component can be evaluated in term of the four samples of the supply voltage as follows:

$$
\left[\begin{array}{l}
u_{1} \\
v_{1} \\
u_{5} \\
v_{5}
\end{array}\right]=A^{-1}\left[\begin{array}{c}
V_{\text {supply present }} \\
V_{\text {supply past } 1} \\
V_{\text {supply past } 2} \\
V_{\text {supply past } 3}
\end{array}\right]
$$

The magnitude and the phase of the fundamental harmonic can be found from the following formula:

$$
\begin{gathered}
\left|V_{1}\right|=\sqrt{u_{1}^{2}+v_{1}^{2}} \\
\phi_{1}=\tan ^{-1} \frac{v_{1}}{u_{1}}
\end{gathered}
$$

It is worth to mention that the matrix $A$ still the same even when the fifth harmonic is not available. When the fifth harmonic is not available, the only thing happens is that the values of $u_{5}$ and $v_{5}$ would be equal to zero, and the fundamental values would not be affected because the two harmonics are independent.

Increasing the number of harmonics can increase the sensitivity of this technique, but that will increases the number of equations as well as the number of sampled values as follows:

\section{Number of Equations $=2 *$ number of harmonics}

The advantages of this method can be listed as:

1. The matrix $A$ depends on $\mathrm{T}$ and $\omega$, so it has a constant value that can be calculated for one time, so matrix $A$ does not require any real time processing.

2. Only four samples are required to perform the detection process, so it requires a small memory size.

3. The small number of samples also results in fast detection for the voltage sag.

4. The results of this method can directly be interpreted because it demonstrates the instantaneous value of the magnitude and phase of the supply voltage.

\section{Simulation RESUltS}

Fig. 2 illustrates the structure of the proposed topology for voltage sag compensation with Numerical Matrix Detection Method attached to the voltage sag detection circuit suggested in [17].

Where $\left(\mathrm{L}_{1}=5 \mathrm{mH}, \mathrm{C}=20 \mu \mathrm{F}, \mathrm{L}_{\mathrm{f}}=10 \mathrm{mH}, \mathrm{C}_{\mathrm{f}}=600 \mu \mathrm{F}, \mathrm{R}=100 \Omega\right.$, line frequency $=50 \mathrm{~Hz}$, and switching frequency $=8 \mathrm{KHz}$, by using the MATLAB simulation environment. Consider that the DVR proposed in [17] can compensate voltage sag up to $70 \%$ of the rated voltage. The algorithm used in Numerical Matrix Detection Method is implemented using MATLAB user defined function ( $\mathrm{fcn}$ ) block whose code is given in Fig. 3 with sampling time $(T=0.0015 \mathrm{sec})$ and fundamental frequency $\left(f_{1}=\frac{\omega_{1}}{2 \pi}=50 \mathrm{~Hz}\right)$. 


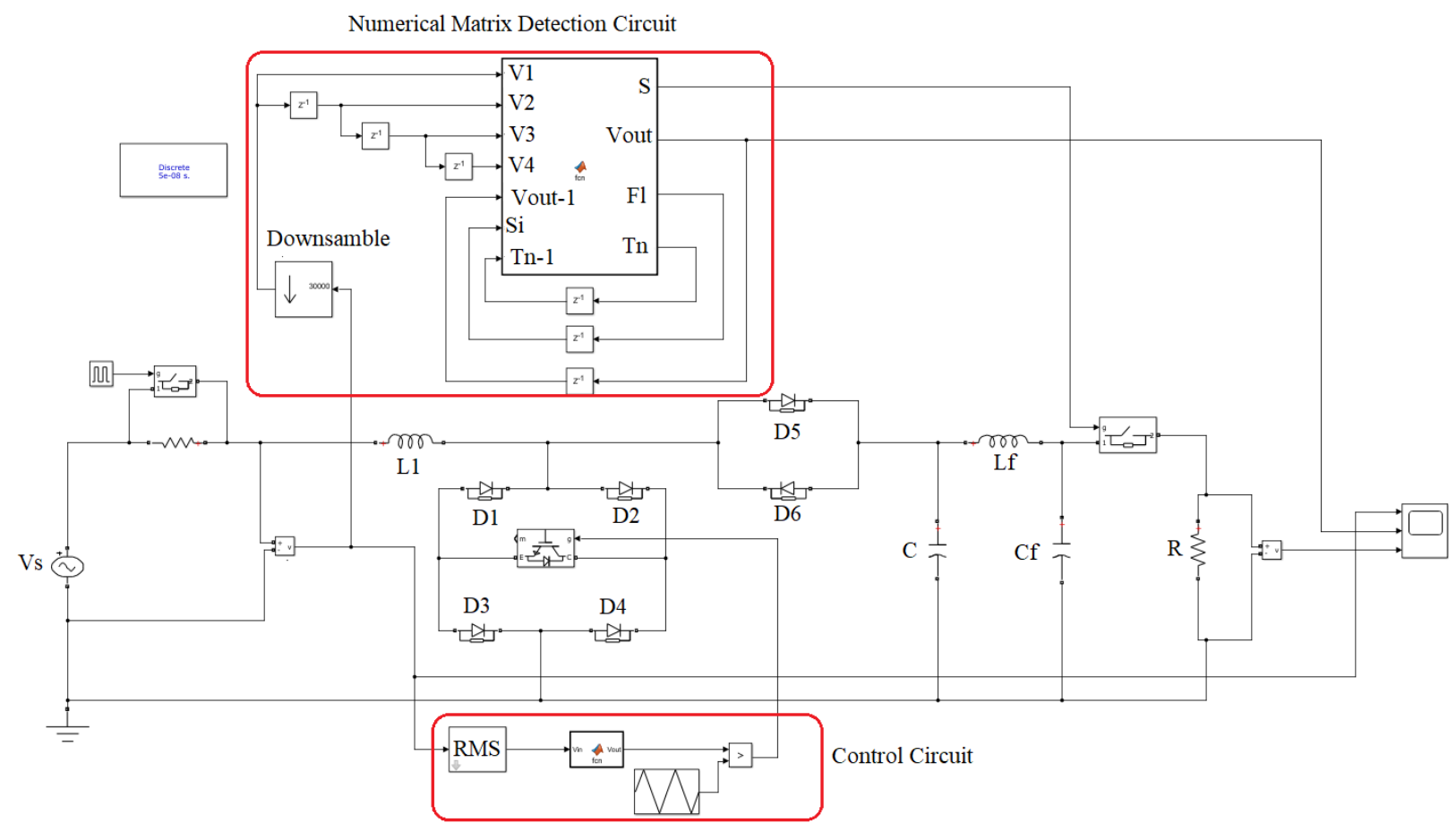

Fig. 2: Voltage sag compensation circuit with the proposed detection technique.

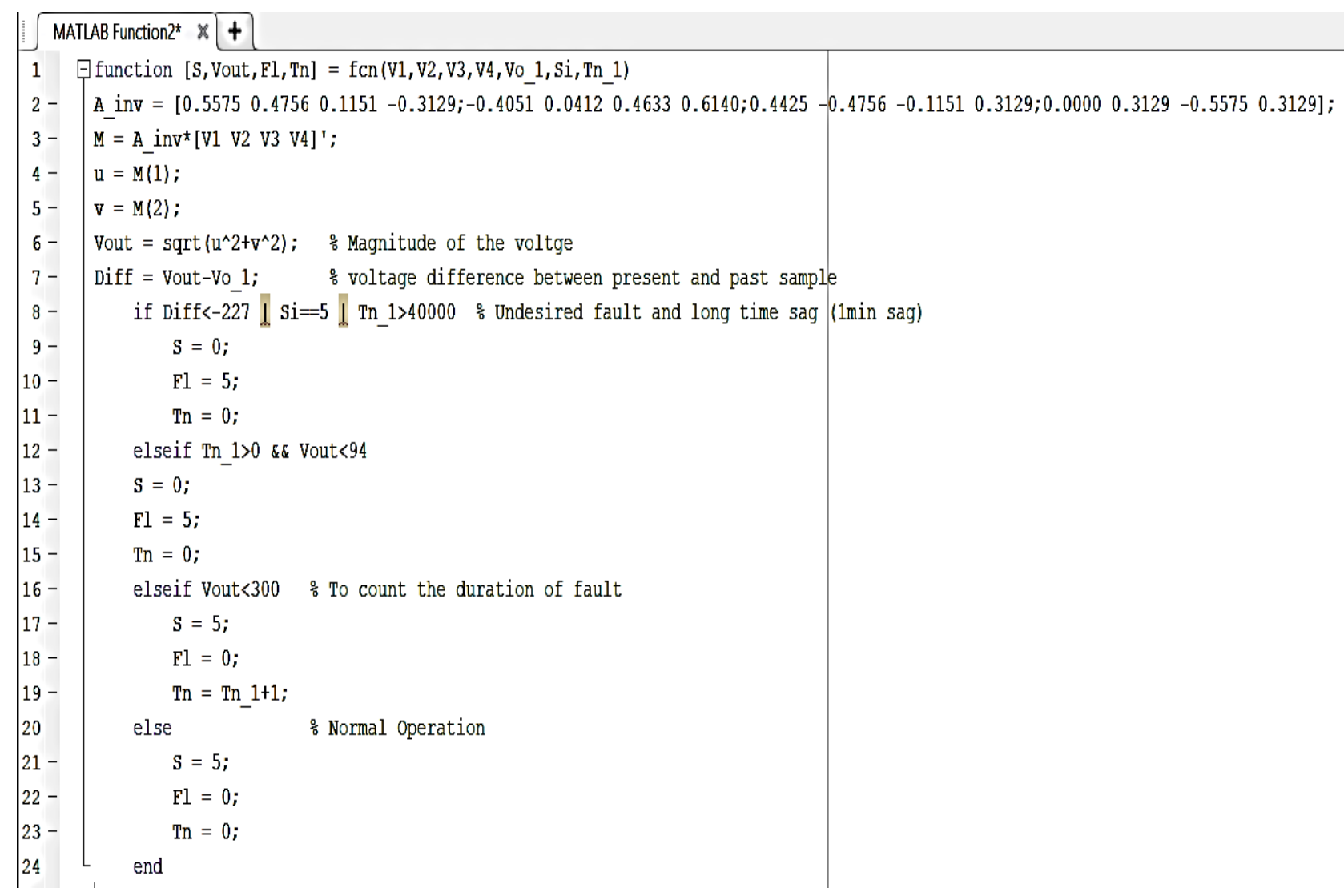

Fig. 3: The algorithm used in Numerical Matrix Detection Method. 
The proposed algorithm for Numerical Matrix Detection Method can be summarized by the following four steps:

- $\quad$ Build the matrix $A$ using Equation (13).

- $\quad$ Find the inverse of the matrix $A$.

The above steps are performed separately for one time because the matrix $A$ depends on constants $\left(T, \omega_{1}\right.$, and $\left.\omega_{5}\right)$. After that the real time algorithm precedes as follows:

- Catch four samples $\left(V_{1}, V_{2}, V_{3}, V_{4}\right)$ and from Equations (14), both real $\left(u_{1}\right.$ and $\left.u_{5}\right)$ and imaginary $\left(v_{1}\right.$ and $\left.v_{5}\right)$ parts for each harmonic component are calculated.

- The magnitude and phase for each harmonic are calculated from Equations (15) and (16).

The above steps are listed in the MATLAB code given in Fig. 3 up to step 6. Starting from step (7), the following conditions are considered:

\section{Condition One: Undesired Fault}

If the supply voltage drops suddenly to more than $70 \%$ of its rated value (less than 94 volt peak of $311 \mathrm{~V}$ ), then the detection algorithm will be recognize this abrupt change as an undesirable disturbance. Therefore, the signal $(S=0 \mathrm{~V})$ is sent to the switch shown in Fig. 2 to disconnect the load from the DVR compensation circuit. Meanwhile, the flag signal is set to $(F l=5 V)$ to indicate the presence of the fault as well as the present fault duration counter is set to zero $\left(T_{n}=0\right)$ to terminate the fault duration counting process. In Fig. 4, the supply voltage suddenly drops from 311 volt to 87 volts at $0.15 \mathrm{sec}$. due to fault. The numerical matrix algorithm detects the disturbance at $0.153 \mathrm{sec}$. (after $0.003 \mathrm{sec}$.) and sends a signal to the switch to disconnect the load.

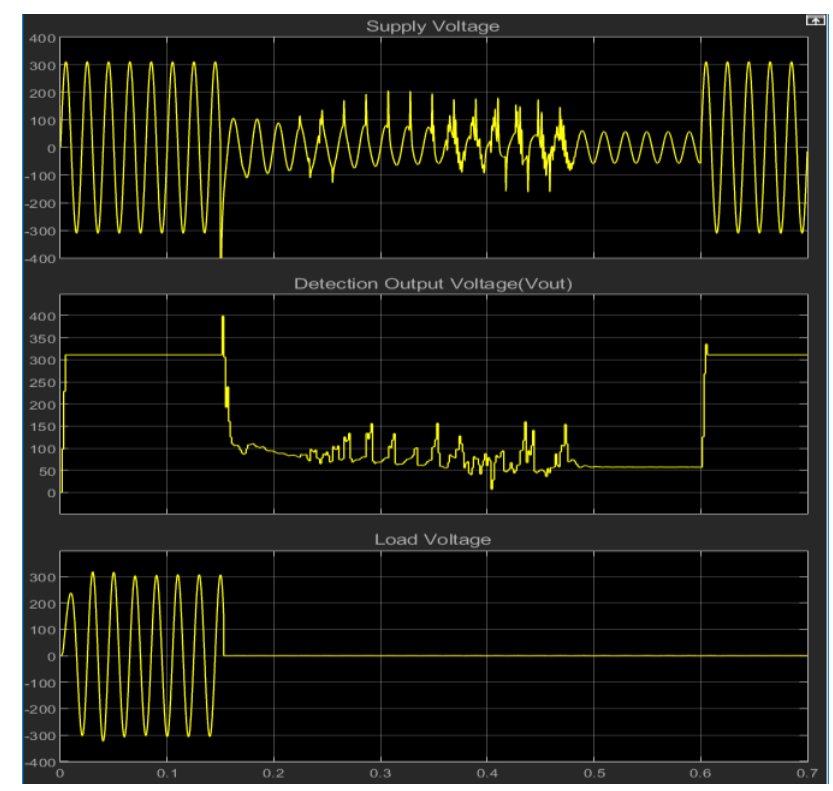

Fig. 4: Response of the Numerical Matrix Detection algorithm due to the presence of undesired fault.

\section{Condition Two: Compensatable Disturbances}

This condition will be studied in three different modes depending on the voltage sag causes as follows:

\section{a) Suddenly Voltage Sag Due to Fault}

The faults can be considered as the main reason of voltage sag [18][19]. Any decrease in the supply voltage occurs with the range of $10 \%$ to $70 \%$ (the capability of the proposed compensation circuit in [17]) can be detected by the numerical matrix detection circuit and recognized as compensatable disturbance. A signal of $5 \mathrm{~V}(S=5 \mathrm{~V})$ will be sent to the switch to be ON. As a result, the load remains connected to the compensation circuit. The timer shown in Fig. 2 will start to count $\left(T_{n}=T_{n_{1}}+1\right)$ in order to determine the sag duration time. Fig. 5 and 6 demonstrate the ability of the numerical matrix detection circuit to distinguish the abrupt change in supply voltage and send a signal to DVR circuit to compensate the missing voltage. Also it can be observed that the detection output voltage $\left(\mathrm{V}_{\text {out }}\right)$ during this type of disturbances has sharp edges at the beginning and the end of the sag. This type of voltage sag is classified as a rectangular voltage sag as in [18].

b) Shallow Voltage Sag According to

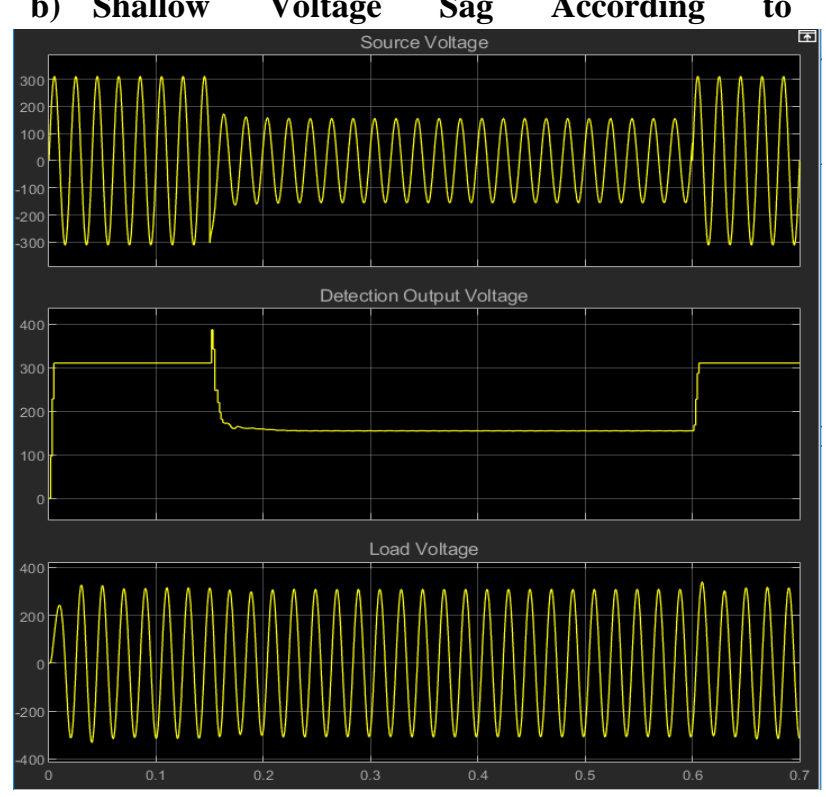

Fig. 5: Response of Numerical Matrix Detection algorithm due to $50 \%$ voltage sag.

\section{Transformer Energization and Starting of Induction Motor:}

The voltage sag occurs due to transformer energizing can be considered as shallow sag. The reduction in the supply voltage is within the range $2 \%$ to $15 \%$ of the rated supply voltage [19]. When the current increases suddenly to about ten times of its rated values during the transformer energization, the voltage does not be decrease suddenly because the flux of the transformer 


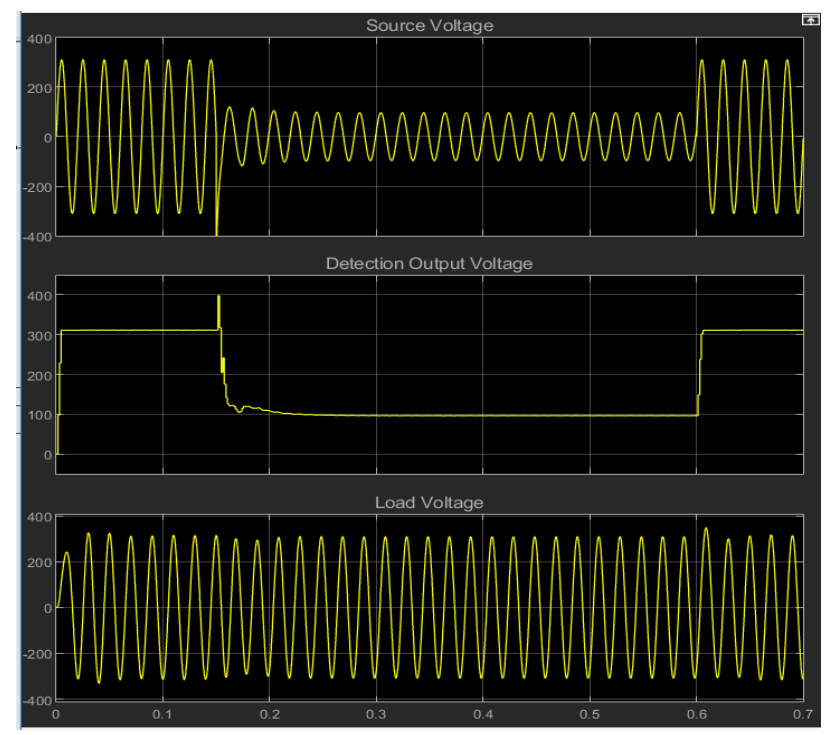

Fig. 6: Response of Numerical Matrix Detection algorithm due to $70 \%$ voltage sag.

cannot suddenly because of its continuous behavior [20]. Furthermore, the drawn current from the induction motor at the starting can be considered as one of causes of voltage sag [19]. The presence of the voltage sag also can be considered as shallow sag within about $6 \%$ of the supply voltage. In both cases, the numerical matrix detection circuit can detect the disturbance and specify it as a compensatable voltage sag. Fig. 7 illustrates the fast detection of $15 \%$ voltage sag using the numerical matrix method and the perfect compensation of the missing voltage effectively by the DVR circuit. From Fig. 7, it can as a non-rectangular voltage sag [18].

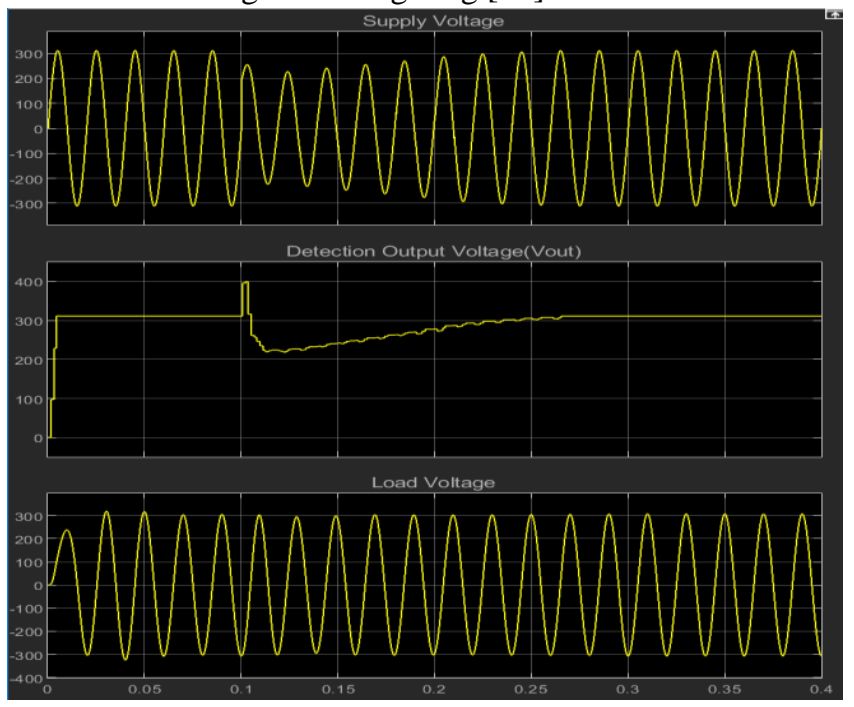

Fig. 7: Response of Numerical Matrix Detection algorithm due to $15 \%$ energization voltage sag.

\section{Condition Three: Long Time Voltage Sag}

This mode of operation simulates the long time duration voltage sag (more than one minute). It is known that according to the IEEE Standard 1159-1995 [2] states that the time duration of the compensatable voltage sag begin from half cycle to one minute. For this reason the numerical matrix detection algorithm considers any voltage sag with time duration more than one minute $\left(T_{n}=40000\right.$ sample) as an undesired disturbance. Therefore, the algorithm sends a signal $(S=0 \mathrm{~V})$ to the switch to isolate the load from the compensation circuit. Fig. 8 illustrates the response of the detection circuit to the long time voltage sag.

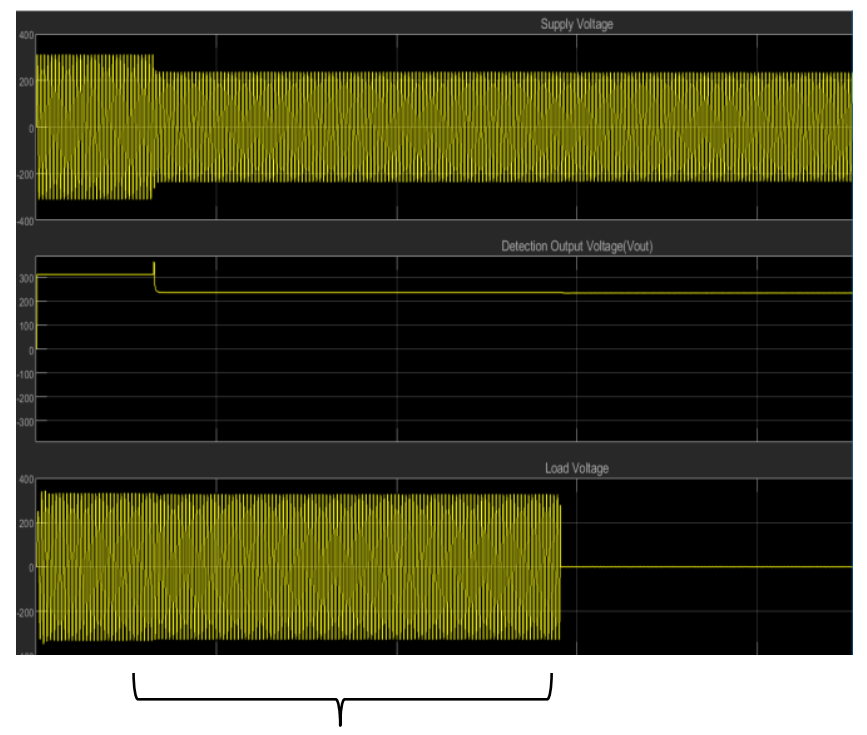

\section{$1 \mathrm{~min}$}

Fig. 8: Response of Numerical Matrix Detection algorithm due to long time sag.

The main benefits of this technique on all other methods are: the matrix $A$ depends on $\mathrm{T}$ and $\omega$, so it has a constant value that can be calculated for one time, so matrix $A$ does not require any real time processing, only four samples are required to perform the detection process, so it requires a small memory size, the small number of samples also results in fast detection for the voltage sag, and the results of this method can directly be interpreted because it demonstrates the instantaneous value of the magnitude and phase of the supply voltage.

\section{CONCLUSION}

This paper has presented a voltage sag detection technique based on the numerical matrix detection method. This detection method has been explained in detail in this work. The numerical matrix method requires a small memory size to store just four samples of the supply voltage, and it does not require an online processing to build its main structural matrix $A$. The algorithm of the numerical matrix detection is attached to an efficient boost converter to demonstrate the reliability of this method in compensating the voltage drop 
caused by the voltage sag. The results show that the numerical matrix detection method can detect the fault in less than $3 \mathrm{~ms}$ for sampling time equal to $1.5 \mathrm{~ms}$. In addition, by studying three different voltage sag patterns, the proposed technique can recognize different voltage sag conditions, and it introduces different response for each voltage sag condition, as a future work the detection circuit will be implemented practically in order to verify the simulation results.

\section{CONFLICT OF INTEREST}

The authors have no conflict of relevant interest to this article.

\section{REFERENCES}

[1] H. J. Bollen, Understanding Power Quality Problems, $2^{\text {nd }}$ ed., John Wiley \& Sons, 2000, pp. 143-148.

[2] IEEE Recommended Practice for Monitoring Electric Power Quality, "IEEE Standard 1159-1995,” 1995.

[3] Y. Lu, G. Xiao, B. Lei, X. Wu, and S. Zhu, "A Transformer less Active Voltage Quality Regulator with the Parasitic Boost Circuit," IEEE Transaction Power Electronics, vol. 29, no .4, pp. 1746-1756, April 2014.

[4] J. Praveen, P. Bishnu, M. S. Venkateshwarlu, and H. V. Makthal, "Review of dynamic voltage restorer for power quality improvement," IEEE Industrial Electronics Society, vol. 1, no. 1 pp. 749-752, 2004.

[5] T. Jimichi, H. Fujita, and H. Akagi, "A dynamic voltage restorer equipped with a high-frequency isolated DCDC converter," IEEE Transactions on Industry Applications, vol. 47, no. 1, pp. 169-175, Jan./Feb. 2011.

[6] W. E. Brumsickle, R. S. Schneider, G. A. Luckjiff, D. M. Divan, and M. F. McGranaghan, "Dynamic Sag Correctors: Cost-Effective Industrial Power Line Conditioning," IEEE Transactions on Industry Applications, vol. 37, no. 1, pp. 1339-1344, Feb. 2001.

[7] C. Z. Noronha, and S.B. Karapurkar, "Design of Active Voltage Regulator for Voltage Sag Mitigation," GRD Journals, vol. 2, no. 4, pp. 85-95, 2017.

[8] M. V. K. Perera, Control of a Dynamic Voltage Restorer to Compensate Single Phase Voltage Sags, Stockholm University, 2007.

[9] C. Fitzer, M. Barnes and P. Green, "Voltage Sag Detection Technique for a Dynamic Voltage Restorer," IEEE Transactions on Industry Applications, vol. 40, no. 1, pp. 203-212, Jan./Feb. 2004.

[10] M. Inci, M. Buyuk, and M. Tumay, "FFT based reference signal generation to compensate simultaneous voltage sag/swell and voltage harmonics," IEEE 16th International Conference on Environment and Electrical Engineering (EEEIC), 2016.

[11] V. A. Skolota \& G. S. Zinovev, "Detecting Voltage Swell, Interruption and Sag," IEEE 19th International Conference of Young Specialists on
Micro/Nanotechnologies and Electron Devices (EDM), 2018.

[12] C. Prakash and N. Suparna, "Design and Simulation of Phase-Locked Loop Controller Based Unified Power Quality Conditioner Using Nonlinear Loads," International Journal of Power Electronics and Drive System (IJPEDS), vol. 2, no. 4, pp. 417-423, 2012.

[13] A. K. Ramasamy, R. K. Iyer, R. N. Mukerjee, and V. K. Ramachandramurthy, "Dynamic Voltage Restorer for voltage sag compensation,", IEEE Power Electronics and Drive Systems (PEDS), vol. 2, no.1, pp. 1289-1293, 2005.

[14] J. R. C. Pearanda and G. Ramos, "Characterization of voltage sags due to faults in radial systems using threephase voltage ellipse parameters," IEEE Transactions on Industry Applications, vol. 54, no. 3, pp. 2032 2040, 2018.

[15] J. G. Nielsen, M. Newman, H. Nielsen, F. Blaabjerg, "Control and testing of a Dynamic Voltage Restorer at medium voltage level," IEEE transactions on Power Electronics, vol. 19, no. 3, pp. 806-813, May 2004.

[16] F. R. Zaro, M. A. Abido, "Real-Time Detection and Classification for Voltage Events Based on Wavelet Transform," IEEE Jordan International Joint Conference on Electrical Engineering and Information Technology (JEEIT), 2019.

[17] A. R. Diwan and K. M. Abdulhasan, "Proposed Topology for Voltage Sag Mitigation with New Control Strategy," Iraqi Journal of Electrical and Electronic Engineering vol. 15, no. 2, pp. 138-144, 2019.

[18] M. Manjula, A. V. R. S. Sarma, and S. Mishra, "Detection and Classification of Voltage Sag Causes based on Empirical Mode Decomposition," Annual IEEE India Conference, 2011.

[19] D. V. Tien, R. Gono, and Z. Leonwicz, "Analysis and Simulation the Causes of Voltage Sags Using EMTP," IEEE International Conference on Environment and Electrical Engineering, 2017.

[20] C. Li, J. Yang, Y. Xu, Y. Wu, and P. Wei, " Classification of voltage sag disturbance source using fuzzy comprehensive evaluation method," IET Journals, $24^{\text {th }}$ International Conference \& Exhibition on Electricity Distribution, 2017. 